\title{
Justiça como autonomia dos indivíduos
}

\section{Justice like individual autonomy}

\author{
Lucilda Selli \\ Universidade do Vale do Rio dos Sinos (UNISINOS), São Leopoldo, \\ Rio Grande do Sul, Brasil. \\ lucilda@unisinos.br \\ Eloir Antonio Vial \\ Unidade Básica de Saúde, Canoas, Rio Grande do Sul, Brasil. \\ eloirvial@ig.com.br
}

\begin{abstract}
Resumo: A bioética, ao compartilhar a aspiração de maior justiça e redução das disparidades sociais, tem papel central no sentido de mediar a justiça como eqüidade no âmbito da lei e como autonomia no campo da ética. O presente artigo busca delimitar o conceito de justiça como autonomia, que vige no mundo da ética. O estudo se sustenta no tripé: a ação humana como conduta que se apóia em critérios, a igualdade como fundamento das relações interpessoais e a pessoa como sujeito da ética.
\end{abstract}

Palavras-chave: Justiça como autonomia. Ação humana. Igualdade. Pessoa.

\begin{abstract}
Bioethics, sharing with the wishes of conquering a major justice and also reducing the social disparity, plays an important role mediating the justice as equity in the law field and the autonomy in the ethics field. The present study tries to establish the current ethical concept of justice as autonomy. This study is based on the tripe: human action as a criteria conduct, equality as the foundation for the interpersonal relations and people as ethics subject.
\end{abstract}

Key words: Justice as autonomy. Human action. Equality. Person.

Foi o pensamento grego o primeiro a refletir racionalmente sobre o mundo social com suas diferenças específicas em relação ao mundo da natureza. Dentre seus múltiplos filósofos, porém, é Aristóteles em quem encontramos uma análise sistemática das diferenças. Uma leitura atenta da Ética a Nicômaco revela as características específicas da ética. Esta tem como objeto o que o autor chama de mundo da liberdade ou ethos, que é o mundo da ação humana, em oposição ao 
mundo da necessidade ou phisis, que é o mundo da natureza, onde vigem leis necessárias e independentes da vontade e da ação humana. Se, no mundo do ethos, os seres humanos são livres para agir, tal liberdade não é absoluta. A conduta humana é sujeita a muitos limites, entre eles, os limites estabelecidos pelas regras, sejam elas políticas ou éticas. Assim se expressa Aristóteles:

“... e no caso das ciências exatas e auto-suficientes não há deliberação... ao contrário as coisas que são realizadas pelos nossos esforços, mas nem sempre do mesmo modo, essas são objeto de deliberação... parece, pois, como já ficou dito, que o homem é um princípio motor de ações; ora, a deliberação gira em torno de coisas a serem feitas pelo próprio agente..." (1).

Uma questão que surge e é importante para a compreensão da justiça como autonomia, é a seguinte: como separar política e ética? A interpretação usual se limita a estabelecer compartimentos estanques para ambas, ou, no pior dos casos, a confundir essas instâncias da vida social. Em verdade, existe um continuum entre as mesmas, pois uma e somente uma é a sociedade. Se examinarmos a vida social, levando em conta a totalidade de seus membros, criando normas cogentes para estimular a cooperação e estabelecer a justiça entre seus membros, fazemos política; se considerarmos os indivíduos ou grupos de indivíduos em seus papéis específicos (filho, pai, amigo, professor, aluno), criando normas para sua conduta, sem o caráter cogente das normas jurídicas, fazemos ética.

Exemplo disso são as relações de amizade, filiais, amorosas etc, todas compostas por uma série de regras, que estão sob o domínio da ética. A política é o lócus onde são produzidas as normas jurídicas; onde se busca, por meio da ação repressiva, direta ou indireta, do Estado, a paz entre os cidadãos e a justiça social. Segundo a Constituição da República Federativa do Brasil de 1988, Art. 50: "Todos são iguais perante a lei, sem distinção de qualquer natureza" (2). Nesse processo cabe à ética um papel relevante. Em geral, a ação política é guiada por princípios éticos que estabelecem as justificativas para a produção de normas jurídicas, já que o político, antes de ser um cidadão, é uma pessoa. 


\section{Revista Brasileira de Bioética}

Em linguagem moderna diríamos que a cidadania se exercita na sociedade política, no Estado, e a pessoa - o titular de direitos e deveres éticos - exerce sua moralidade na sociedade civil. Aristóteles ${ }^{1}$ chama a pessoa de "homem de bem" para diferenciá-lo do cidadão. Assim encontramos em Engelhardt:

“... as pessoas, e não os seres humanos, são especiais - pelo menos se tudo o que temos é moralidade secular geral. Os humanos moralmente competentes têm uma posição moral central que não é desfrutada pelos fetos ou mesmo pelas crianças pequenas. Somente as pessoas escrevem e lêem livros de filosofia. São elas que constituem a comunidade moral secular, preocupam-se com argumentos morais e podem ser por eles convencidas... é preciso ter a auto-reflexão da autoconsciência" (3).

Logo, nem todos os membros da coletividade podem ser considerados pessoas, strictu senso; para tanto, é necessário que sejam juridicamente e, mais do que isso, moralmente competentes. Noutras palavras, devem preocupar-se com argumentos morais e podem ser por eles convencidos; além do mais, as relações interpessoais de cunho ético, ao contrário das relações políticas, não envolvem o fenômeno da dominação, devendo resultar em relações sociais igualitárias e, portanto, democráticas.

\section{Justiça como autonomia}

No mundo jurídico, o conceito de justiça está ligado ao conceito de regra, norma ou lei jurídica, que é produzido pelo sistema político, na figura do legislador. Segundo Aristóteles:

“... como vimos que o homem sem lei é injusto e o respeitador da lei é justo, evidentemente todos os atos legítimos são, em certo sentido, atos justos: porque os atos prescritos pela arte do legislador são legítimos, e cada um deles, dizemos nós, é justo" (1).

Esta forma de justiça é, por isso, a que deriva da lei, ou ex lege. E o princípio ético geral que orienta tal forma de justiça é: cuique 
suum tribuere (a cada um o seu). Vemos, assim, que a igualdade é a fórmula mais adequada para a justiça, embora, seja difícil estabelecer tal igualdade nas questões humanas. Na verdade, o direito busca restabelecer uma relação de igualdade que precede a transgressão de um direito subjetivo. Busca, portanto, restabelecer a situação anterior ao evento. Quando é impossível restabelecer a igualdade, busca a lei, ao menos restabelecer uma igualdade proporcional e, se não a restabelece na íntegra, o faz de forma proporcional.

A segunda forma de justiça, utilizada na ética e que nos interessa aqui, diz respeito ao tratamento moral que todos os membros da coletividade esperam receber enquanto seres humanos dotados de dignidade. Assim, de acordo com Rawls:

"Se todos os membros da coletividade cooperam entre si, embora com posições distintas na divisão do trabalho, que critério de justiça deve ser utilizado como parâmetro para estabelecer os méritos de cada um e que darão acesso aos bens sociais que estarão ligados a tais méritos?" (4).

Noutras palavras, as desigualdades socioeconômicas verificadas nas economias de mercado, causadas pela desigual distribuição de renda, são eticamente injustas, embora legalmente justas, com a conseqüente distinção entre justo legal e justo moral. Segundo o autor cabe, então, a criação de um conceito político de justiça para manter a coesão social, que Rawls chama de justiça como eqüidade. Conforme esse conceito a eqüidade deve ser tomada em seu sentido clássico aristotélico de correção da justiça legal, quando, por um motivo qualquer (obscuridade da norma, lacuna da mesma etc.), a norma existente não estabelece o cuique suum. Tal eqüidade tem a função de restabelecer a justiça na distribuição social da riqueza. Rawls (5) baseia-se em dois princípios que são uma reinterpretação da tradicional divisão da justiça em comutativa e distributiva. Para o autor, pela justiça comutativa, cada pessoa deve ter a mais ampla liberdade, sendo que esta deve ser igual a dos outros e a mais extensa possível, na medida em que seja compatível com uma liberdade similar de outros indivíduos. Pela justiça distributiva, refere o princípio da diferença. Assim, as desigualdades econômicas e sociais devem ser 


\section{Revista Brasileira de Bioética}

combinadas de forma que correspondam à expectativa de que trarão vantagens para todos e que sejam ligadas a posições e instituições abertas a todos.

Nosso objetivo, entretanto, difere do objetivo de Rawls. A justiça como eqüidade, para este autor, refere-se à dimensão política da vida social, na qual, preferencialmente, se estabelece o acesso aos bens sociais escassos (dinheiro, prestígio, poder) e também à forma com que os mesmos podem ser entregues às próximas gerações (herança). Em nossas considerações trata-se de estabelecer a concepção de justiça nas relações entre os membros da sociedade civil. A diferença é que não se trata de distribuir bens escassos ou punir condutas antijurídicas, mas viabilizar a igualdade para todos na possibilidade de desenvolverem sua autonomia ética. Esta é definida aqui como capacidade da pessoa humana de estabelecer os fins para sua conduta, em função de seu código de valores, de escolher os meios adequados para atingilos, com base numa apreciação pessoal dos resultados futuros do seu agir. Entendemos, portanto, a justiça, no sentido ético, como respeito à autonomia dos indivíduos.

Segundo Bobbio (6), o mundo moderno interiorizou a noção de sujeição às leis. Em outros termos, a coação exterior da comunidade sobre os seus membros, baseada em normas jurídicas ou morais e consubstanciada na tradição, cedeu lugar à autoprodução individual das normas jurídicas ou morais. Liberdade, assim, é a capacidade de produzir normas para si próprio. Em seu entender, a primeira ampliação do conceito de liberdade ocorreu com a passagem da teoria da liberdade como não-impedimento, para a teoria da liberdade como autonomia: quando liberdade passou a ser entendida não mais apenas como o não impedimento por normas externas, mas, como o dar leis a si próprios. Portanto, não tanto como o não ter leis, tal como entendia Hobbes (7), mas sim como o obedecer a leis estabelecidas por nós para nós mesmos. Com o conceito de autonomia, a liberdade não consiste mais na ausência de leis, mas sim na presença de leis intimamente desejadas e internamente estabelecidas. Rousseau, citado por Bobbio (6), quando afirmou, no Contrato social, que a "liberdade é a obediência à lei que prescrevemos a nós mesmos", deu-nos a mais perfeita definição desse novo conceito de liberdade no mundo da ética.

Nesta linha de raciocínio e sob uma perspectiva histórica, pode- 
mos verificar que foi o pensamento grego o primeiro a estabelecer distinção entre mundo da necessidade e mundo da liberdade. No primeiro, são estabelecidas as relações entre os homens e a natureza; no segundo, as relações dos homens entre si. No mundo da necessidade os homens são premidos pela sobrevivência; no mundo da liberdade, que é o reino da ética, podem desenvolver plenamente sua humanidade. No primeiro, o valor fundamental é a justiça como eqüidade; no segundo, o valor fundamental é a justiça como autonomia.

Aristóteles (1) opõe o ethos à phisis, como sendo um âmbito que ainda que também seja comandado por regras, não conhece as leis da natureza, a não ser a mutabilidade e regularidade das posturas humanas e de suas formas de comportamento. Por isso, o imperativo categórico kantiano (8), segundo o qual devemos tratar os outros como fim e não como meio, é insuficiente para estabelecer a justiça do ponto de vista que aqui consideramos. Kant imaginava uma comunidade racional universal, pressupondo o que deve ser uma busca incessante: a autonomia de cada pessoa. No nosso entender, cabe ao agente, com uma visão crítica do mundo social, tudo fazer para que o outro se descubra autônomo.

Esta é a justiça que se aplica no mundo ético, com o nome de justiça como autonomia, que tem por teatro a sociedade civil e que pode ser definida como: todos os membros de uma comunidade moral devem ver a si mesmos e aos demais, em suas relações, como igualmente autônomas. Quando tal não ocorre, devemos tudo fazer para que a autonomia prevaleça.

\section{Ação humana como conduta que se apóia em critérios}

Segundo o modelo clássico de interpretação da ação humana, desenvolvido por Aristóteles (1), a conduta humana é predominantemente teleológica (finalista), e busca sempre um resultado previamente estabelecido pelo agente. São elementos da ação humana: desejo (busca do resultado da conduta); escolha (dos meios necessários para atingir tal resultado); vontade (início efetivo da ação); e resultado ou consumação do desejo. Partindo deste pressuposto, Weber (9), construiu a seguinte tipologia para a ação humana: ação racional com relação a um objetivo (ou fim); ação racional com relação a um valor; 


\section{Revista Brasileira de Bioética}

ação afetiva ou emocional; e ação tradicional. Racional, segundo Weber, é toda conduta que se apóia subjetiva ou objetivamente em critérios capazes de orientar a ação humana em todos os campos de atividade. A ação racional com relação a um objetivo é exemplificada pelo engenheiro que constrói uma ponte, o empresário que busca o lucro, o consumidor que procura maximizar seus recursos etc. $\mathrm{O}$ agente sabe exatamente o que quer (objetivo) e utiliza os meios adequados para atingir tal fim. A ação racional com relação a um valor, como o próprio nome diz, se remete ao mundo da moralidade, com seus valores, princípios e máximas. Kant (8) entende valor como um imperativo moral; um dever-ser que serve de guia para orientar e dar sentido à conduta prática dos indivíduos.

A gênese dos valores pode ser vista de um duplo ponto de vista: os valores podem ter como fundamento tanto a figura divina (como no caso do cristianismo) ou uma concepção metafísica dos mesmos (como é o caso da justiça em Platão, ou do bem em Aristóteles), quanto, uma concepção imanente dos mesmos (que vê no homem o fundamento da ética). Nas palavras de Sartre:

“... se suprimo a Deus pai, nos fará falta alguém que invente os valores... Dizer que nós inventamos os valores significa unicamente que a vida carece de sentido a priori. Antes de vivê-la não é nada; porém, é a nós a quem compete dar-lhe um sentido, e, o valor não é nada mais que esse sentido que elegemos" (10).

Assim, ação racional com relação a um valor é, por exemplo, a do médico que se recusa a realizar um aborto, por motivo de crença religiosa; de um enfermeiro que assiste a um enfermo. A ação é racional porque busca preservar os valores que o agente estabeleceu como fundamento de sua conduta pessoal e profissional e, portanto, deve permanecer fiel a eles. A ação afetiva ou emocional, para Weber (9), é aquela ditada pelo estado emocional presente no indivíduo, no momento em que age. É o xingamento ao juiz feito pelo torcedor no campo de futebol; a reprimenda da mãe ao filho inquieto; são as juras de amor dos enamorados etc. A ação tradicional é aquela ditada pelos hábitos, costumes, crenças, que se transformam numa segunda natureza dos seres humanos, não mais passando pelo crivo da razão. Para 
agir segundo as crenças ou a tradição, o agente não precisa estabelecer um objetivo, seguir um valor ou ser impelido pela emoção. Segue apenas condicionamentos enraizados em seu inconsciente, após longo processo de socialização.

Merece referência, o fato de que toda ação humana se faz no tempo e no espaço e é limitada pelas circunstâncias. Assim, as circunstâncias são elementos importantes da ação dos indivíduos, que perfazem o domínio do que se pode chamar mundo ético.

\section{Igualdade: fundamento das relações interpessoais}

Este termo, central em disciplinas como ética, política, direito e outras, designa, em geral, conceitos distintos que só um estudo da sua gênese histórica pode esclarecer. A primeira forma de igualdade que se desenvolveu no Ocidente estava ligada à religião cristã. Foi o cristianismo o primeiro a demonstrar que todos são iguais perante Deus. Assim, Paulo, na Carta aos Romanos, capítulo 2, versículo 11, afirma: "Diante de Deus não há distinção de pessoas" (11). No Livro da Sabedoria, capítulo 6, versículo 7, encontramos: "O Senhor de todos não fará exceção para ninguém, e não se deixará impor pela grandeza, porque pequenos ou grandes, é Ele que a todos criou, e de todos cuida igualmente" (11). Até então, na civilização greco-romana, prevalecia um conceito aristocrático de igualdade, reservado para as classes dominantes.

Foi Hobbes o primeiro a enunciar a igualdade humana como um fato natural, estabelecendo as bases teóricas para um amplo movimento igualitarista:

"A natureza fez os homens tão iguais, quanto às faculdades do corpo e do espírito, que embora por vezes se encontre um homem manifestamente mais forte de corpo, ou de espírito mais vivo do que outro, mesmo assim, quando se considera tudo isso em conjunto, a diferença entre um e outro homem não é suficientemente considerável para que qualquer um possa com base nela reclamar qualquer benefício a que outro não possa também aspirar, tal como ele" (7). 


\section{Revista Brasileira de Bioética}

A igualdade política, baseada no estatuto da cidadania, foi reivindicada pela primeira vez por um grupo democrático radical dos puritanos na revolução inglesa de 1642. A si mesmo denominavam nivellers (niveladores) e exigiam o sufrágio universal masculino. Porém, foi com a Revolução Francesa que a cidadania política ganhou vida. Durante a Revolução Francesa outro conceito de igualdade surgiu. Gracus Babeuf, revolucionário que representava a ala esquerda radical da Revolução, no Manifesto dos Iguais, redigido em 1797, pregava a igualdade distributiva.

A igualdade social foi enunciada por Tocqueville, citado por Aron (12), para demonstrar que as profundas modificações que ocorriam na Europa tinham como causa as novas representações que os homens faziam de si mesmos. Segundo Aron, em comentário sobre Tocqueville:

"A democracia consiste na igualização das condições. Democrática é a sociedade onde não subsistem distinções de ordem e de classes; em que todos os indivíduos que compõem a coletividade são socialmente iguais, o que não significa que sejam intelectualmente iguais, o que é absurdo, ou economicamente iguais, o que para Tocqueville é impossível. A igualdade social significa a inexistência de diferenças hereditárias de condições; quer dizer que todas as ocupações, todas as profissões, dignidades e honrarias são acessíveis a todos" (12).

Igualdade social significa a desconsideração das diferenças naturais e sociais entre os seres humanos. Diferenças físicas, de nascimento, riqueza, cultura e outras quaisquer, não são suficientes, segundo Tocqueville, para que alguém se sinta superior a outro e com isso reivindique algo que o outro não possa reivindicar. Essa igualdade social constitui a base das demais formas de igualdade: política, distributiva, jurídica, ética e bioética.

No mundo ético, a igualdade social é o fundamento das relações interpessoais. Por ela, todos os seres humanos são iguais em dignidade e valor, sem qualquer tipo de distinção, seja ela dada pela natureza ou pela vida social. Tal concepção de igualdade tem origem no jusnaturalismo inglês do Século XVII, que tem Hobbes e Locke como seus 
maiores expoentes. Segundo essa teoria - que podemos chamar de "individualismo ético" - o indivíduo é um ser com dignidade e valor absolutos; só ele é fundamento da vida social, econômica, política e moral.

\section{Pessoa como sujeito da ética}

O conceito-chave para a compreensão da conduta ética em geral é o de pessoa. A noção de pessoa desempenha um papel decisivo na ética. Diz Vidal (13), que “... a pessoa é seu sujeito e seu objeto, seu fundamento e seu eixo, seu lugar e sua convergência, de tal modo que, sem a pessoa não temos onde fundamentar a ética".

Para Lepargneur (14): " ... é pessoa o indivíduo consciente, dotado de corpo, razão e vontade, autônomo e responsável". São as pessoas que se conduzem moralmente. É em sua relação com os demais membros da coletividade que se estabelece a motivação ou sentido ético para sua conduta. São pessoas, em sentido amplo, todos os membros da comunidade, inclusive os recém-nascidos. Em sentido estrito, são aqueles indivíduos que, além de serem capazes (no sentido jurídico), são moralmente competentes.

No mundo ético, a conduta humana tem como objetivo ou finalidade a ação moralmente correta. Tal objetivo é atingido pelo querer ético onde a moralidade designa a conduta humana no domínio ético, que a vê não como uma obrigação (baseada na prescrição), mas como um dever que é auto-imposto de forma livre. Esta categoria é central na ótica deste trabalho e deve possuir um significado unívoco.

Definimos como pessoas, os membros da coletividade que desempenham múltiplos papéis ao longo de suas vidas, em suas relações com os demais, papéis esses compostos por regras que atribuem direitos e deveres que possuem a função de regulamentar seu exercício. Pai, filho, professor, aluno, cidadão, por exemplo, são alguns desses papéis. Todos eles, à exceção do papel de cidadão, são desenvolvidos no mundo privado ou da sociedade civil. Com isso, não queremos elidir nem diminuir a dimensão da cidadania, tão em voga nos dias de hoje. Ao contrário, sabemos que as decisões que vinculam as condutas humanas a normas cogentes são tomadas pelo sistema político, no qual o cidadão é soberano. No Art. $1^{\circ}$, Parágrafo Único da Consti- 


\section{Revista Brasileira de Bioética}

tuição da República Federativa do Brasil de 1988, (2), consta: "Todo o poder emana do povo, que o exerce por meio de representantes eleitos ou diretamente, nos termos desta Constituição". É, portanto, a esfera política, o foro por excelência onde os membros da coletividade, principalmente os menos assistidos, podem reivindicar direitos sociais, econômicos etc, que venham ao encontro de suas necessidades materiais.

A definição e a distinção clássica entre os conceitos de pessoa e cidadão foram estabelecidas por Aristóteles, de forma definitiva, na política:

"Os objetos que acabamos de tratar levam-nos agora a examinar se as mesmas virtudes fazem o homem de bem e o bom cidadão... Podem comparar-se os cidadãos aos marinheiros; uns e outros são membros duma comunidade. Ora, embora os marinheiros tenham as suas tarefas muito diversas, um remando, outro estando ao leme, um terceiro vigiando à proa, ou desempenhando qualquer outra função que tem o seu nome próprio, é evidente que as tarefas de cada um formam a sua virtude própria, mas há uma que constantemente é comum a todos, uma vez que todos têm por finalidade a segurança da navegação, a que aspiram e para a qual concorrem, cada qual de sua maneira. Da mesma forma, embora as funções dos cidadãos sejam diferentes, todos trabalham para a conservação de sua comunidade, ou seja, para a saúde do Estado. É, por conseguinte, a este interesse comum que se deve referir a virtude do cidadão .... Que [para ser um homem de bem], por outro lado, cada um execute o melhor possível de suas funções. É nisto que consiste a sua virtude própria (...), o mérito dum homem de bem e o de um bom cidadão são, pois, coisas distintas" (1).

Pessoa é membro da sociedade civil em sentido concreto. Está inserida numa pluralidade de papéis sociais. O espaço da moralidade subjetiva, nesta esfera, é aquela onde a reflexão do indivíduo orienta sua ação; assim, seu agir não está dado pela determinação da lei, mas, pela escolha pessoal, no espaço da sociedade civil. 


\section{Considerações finais}

Esta breve descrição compreende alguns aspectos fundamentais da justiça como autonomia. Embora distante ainda de uma reflexão suficientemente aprofundada, tudo o que se pretende é começar lançando luzes sobre o tema da justiça como um princípio que tem diferentes significados e que por vezes é utilizado de forma indiscriminada, como se pudesse ser utilizada univocamente em todas as instâncias da vida humana.

A justiça como autonomia abriga a pessoa como sujeito autônomo, elege a ação humana pautada em critérios e destaca a igualdade como fundamento das relações interpessoais. Diferente da justiça como eqüidade, que tem no centro de seus interesses a justa distribuição, pelo Estado, de bens e benefícios, a justiça como autonomia prima pela concretização da liberdade de todas as pessoas. Neste sentido, todos os membros da sociedade que compartilham idênticas ou distintas moralidades, devem ver a si mesmos e aos demais, em suas relações, como igualmente capazes de exercerem a autonomia. Quando tal não ocorre, deve-se tudo fazer para que a autonomia prevaleça.

A bioética, em suas ações interventivas, deve primar pela redução das relações sociais assimétricas advenientes, entre outras causas, pela reduzida autonomia a que muitas pessoas são submetidas e, desta forma, ser promotora da justiça em seu sentido amplo, inclusive como autonomia.

\section{Referências}

1. Aristóteles. Ética a Nicômaco. São Paulo: Abril Cultural, 1979. pp. 85 -6; 122; 37-8.

2. Brasil. Constituição da República Federativa do Brasil 1998. São Paulo: Saraiva, 1996.

3. Engelhardt, T. Fundamentos da bioética. São Paulo: Loyola, 1998. pp. 169 -70 .

4. Rawls, J. O liberalismo político. São Paulo: Ed. Ática, 2000. p. 45.

5. Rawls, J. Justicia como equidad. Materiales para una teoría de la justicia. Madrid: Tecnos, 1986. p. 60.

6. Bobbio, N. et al. Dicionário de política. I e II. Brasília: Editora da UnB, 1995. 


\section{Revista Brasileira de Bioética}

7. Hobbes, T. Leviatã ou matéria forma e poder de um Estado eclesiástico e civil. São Paulo: Abril Cultural, 1983. p.54.

8. Kant, I. La metafísica de los costumbres. Madrid: Tecnos. 1989.

9. Weber, M. Conceitos básicos de sociologia. São Paulo: Moraes, 1989.

10. Sartre, JP. O existencialismo é um humanismo. São Paulo: Abril Cultural, 1973. pp.26-7.

11. Bíblia. Bíblia sagrada: antigo e novo testamentos. São Paulo: Difusão Cultural do Livro, 2002.

12. Aron, R. As etapas do pensamento sociológico. Brasília: Ed. da UnB,1987. 13. Vidal, M. Moral de atitudes I. São Paulo: Santuário, 1978.

14. Lepargneur, H. Bioética. Novo conceito - a caminho do consenso. São Paulo: Loyola, 1996.

Recebido em 15/08/2006. Aprovado em 24/09/2006 